\title{
Intervention in Lower-class Surinam-Dutch Families: Effects on Mothers and Infants
}

\author{
J. Marianne Riksen-Walraven, Johannes Th. Meij, \\ Frans O. Hubbard, and Jolien Zevalkink \\ University of Nijmegen, The Netherlands
}

\begin{abstract}
Thirty-seven Surinam-Dutch lower-class families with a one-year-old child participated in "Instapje", a parent-focused home-based intervention programme. The intervention was devised to improve quality of parental support to the child on four behavioural dimensions: supportive presence, respect for the child's autonomy, structure and limit setting, and quality of instruction. The programme was presented to the parents in 16 weekly home-visits, starting when the child was 13 months old. When the children were 18 months of age, intervention group parents were indeed significantly more supportive of their children than parents in a comparable control group of 38 Surinam-Dutch families. Moreover, intervention group children scored significantly higher on the Bayley Mental Scale of Infant Development than children in the control group. No intervention effects were found on quality of the parent-child relationship and on parents' sense of competence in child rearing.
\end{abstract}

In the Netherlands, as in many other countries, children from lower social classes and ethnic minority groups appear to be less successful at school than children from middle and higher class indigenous families. They perform at lower levels of academic achievement throughout the Dutch elementary

Requests for reprints should be sent to J. Marianne Riksen-Walraven, Department of Developmental Psychology, University of Nijmegen, P.O. Box 9104, 6500 HE Nijmegen, The Netherlands, E-mail riksen@psych.kun.nl.

J. Marianne Riksen-Walraven, University of Nijmegen; Johannes Th. Meij, University of Nijmegen (now at the Netherlands Institute of Care and Welfare, Utrecht); Frans O. Hubbard, University of Nijmegen (now at the University of Amsterdam); Jolien Zevalkink, University of Nijmegen.

This research was supported by a grant from the Dutch Department of Welfare, Public Health and Culture. The project was conducted in collaboration with the Surinamese Foundation KROSBE in Rotterdam, The Netherlands. We thank Cornelis F. Van Lieshout, Dymphna C. Van den Boom, Willard W. Hartup, Michael W. Katzko, and two anonymous reviewers for their helpful comments on earlier drafts of this manuscript. 
schools (Tesser, Mulder, \& Van der Werf, 1991), have more graderetentions, and are over-represented in special education (Petersen \& De Keyzer, 1991). Various research data show that these children already lack basic knowledge as well as linguistic and cognitive skills. when they enter kindergarten. Moroccan and Turkish preschoolers, followed by their Surinamese and Antillian agemates, perform in these areas even at lower levels than Dutch children from deprived socioeconomic backgrounds (cf. Pels, 1990). In addition to providing special facilities to schools, the Dutch government has been supporting home-based preschool intervention programmes in order to prevent educational lags in children from disadvantaged families. To that purpose we were invited to develop an intervention programme for disadvantaged families with a child in the second year of life. The development of this programme and its evaluation in a field experiment is described in this paper. The programme was called "Instapje", which means "First step into ..."

The Instapje intervention programme is basically parent-focused. We aimed at enhancing the quality of support parents provide to their young children during daily interactions, assuming that this would contribute to the child's later school success. Developmental and educational studies have documented that the quality of parent-child interaction in the first years of a child's life is associated with child development in several domains that are relevant for later functioning in school. First, children's early experiences during interactions with their parents are assumed to influence their cognitive and language development (Bornstein, 1985; Bruner, 1983; Rogoff, 1990; Vygotsky, 1978). In addition, the quality of early parent-child interaction is related to children's social competence (Elicker, Englund, \& Sroufe, 1993; Suess, Grossmann, \& Sroufe, 1992) and to their ego-resiliency (Arend, Gove, \& Sroufe, 1979; Block \& Block, 1980; Riksen-Walraven, 1991). These, in turn, also contribute to school adjustment (Van Aken, 1992). By teaching parents the skills needed to support their young children better during the early years of development, we hoped to promote their competence and self-confidence as caregivers, thus increasing the likelihood of long-term favourable effects of the intervention. It has been shown that parent-focused intervention may indeed have long-term beneficial effects on the participating parents and children and even on younger siblings of the target child (Gray \& Klaus, 1970; Seitz \& Apfel, 1994).

The Instapje programme was designed for parents with children in the second year of life. In this age period development of autonomy is generally considered a "central developmental issue" for the child (Erikson, 1963; Mahler, Pine, \& Bergman, 1975; Sander, 1975; Sroufe, 1979). In order to support children adequately in acquiring more autonomy, parents have to possess several interactional skills. We assume that adequate support by a parent to a one-year-old child can be defined in terms of four major 
behavioural dimensions (cf. Erikson, Sroufe, \& Egeland, 1985). First of all, it is important for parents to be accessible to their child and to provide adequate emotional support when needed ("supportive presence"). Emotional support is considered as the most important element of parental support already in the first year of life (Erikson, 1963) and is assumed to remain a basic ingredient of support in later years as well. But in the second year of life parents need additional supportive skills to manage and foster their children's growing autonomy. It now becomes increasingly important to let children experience their own competence, which means that the parent respects their autonomy as much as possible ("respect for the child's autonomy"). At the same time, children's strivings toward autonomy call for adequate structuring of the situation and for setting firm and consistent limits to their behaviour ("structure and limit setting"). Finally, somewhat later in the second year, as children's capacity to understand language shows a remarkable increase, parents' ability to provide adequate instructions and information ("quality of instruction") gains importance as a means to help children understand and master their rapidly expanding world. On these grounds, we decided to focus the Instapje programme on improving these four dimensions of parental support.

We designed the Instapje programme specifically for lower class SurinamDutch families. We decided to focus on one cultural minority group because we wanted to gear the intervention as much as possible towards prevailing values, beliefs, and child-rearing practices in the target group. Pedagogical traditions in Surinam, the country of origin of the parents in our target group, differ in several respects from those in the Netherlands (cf. Jap-A-Joe $\&$ Leseman, 1993). Surinamese parents are generally more restrictive and discipline oriented than their Dutch counterparts. They consider obedience and respect for adults as important characteristics for their children, and instil these values already at an early age. Moreover, Surinamese parents in the Netherlands generally lay great value on academic success and have high achievement standards for their children, both for boys and for girls. However, despite their eagerness to invest in their children's education and future, the quality of support Surinam-Dutch parents provide to their children in the first years of life appears to be relatively low. Van IJzendoorn (1990) found that Surinam-Dutch mothers displayed significantly less sensitive responsiveness to their 18-month-old children than Dutch mothers. Moreover, van IJzendoorn reported that Surinam-Dutch mothers experienced child rearing as a heavier burden than Dutch mothers and were more anxious about their children's development. In order to gain more insight into parent-infant interactions and the context of parenting in our target group, we conducted a preliminary study on 10 lower class SurinamDutch families with one-year-old children. The information we obtained from interviews with the parents and from videotaped parent-child 
interactions was used in developing a preliminary version of the intervention programme.

We expected that the intervention would have a positive effect on four groups of outcome measures. The causal model underlying our expectations is depicted in Fig. 1. As the figure shows, the intervention was directly focused on improving quality of parental support on four behavioural dimensions. Therefore, we expected an effect of the programme on these four dimensions in the first place. Given a positive effect on quality of parental support, we also expected improvement of children's cognitive development and of the quality of the parent-child relationship. Associations between parental behaviour in interaction with the child and the children's cognitive development have been found in various cultures, not only in North America (Tamis-LeMonda \& Bornstein, 1994) and Western European countries (Heckhausen, 1987; Riksen-Walraven, 1978; Spangler, 1989), but also in non-Western settings, such as Kenya (Sigman et al., 1988), Egypt (Wachs et al., 1993), and Japan (Tamis-Lemonda, Bornstein, Cyphers, Toda, \& Ogino, 1992). The link between quality of parental support during the early years and quality of the parent-child relationship has also been extensively documented. Parent-infant attachment studies, for example, show that sensitive parents, who provide emotional support when their children need it, have children who feel secure in the presence of their parents and show relatively much positive and little negative affect towards them (cf. Isabella, 1994; Lieberman, Weston, \& Pawl, 1991; Van den Boom, 1994). These "secure" children are also more compliant and co-operative in interaction with their caregivers and more attentive to their communications than children of emotionally less supportive parents (Bus \& Van IJzendoorn, 1992; Matas, Arend, \& Sroufe, 1978). Therefore, their cognitive development might benefit more from information and instructions provided by the caregiver. Finally, we

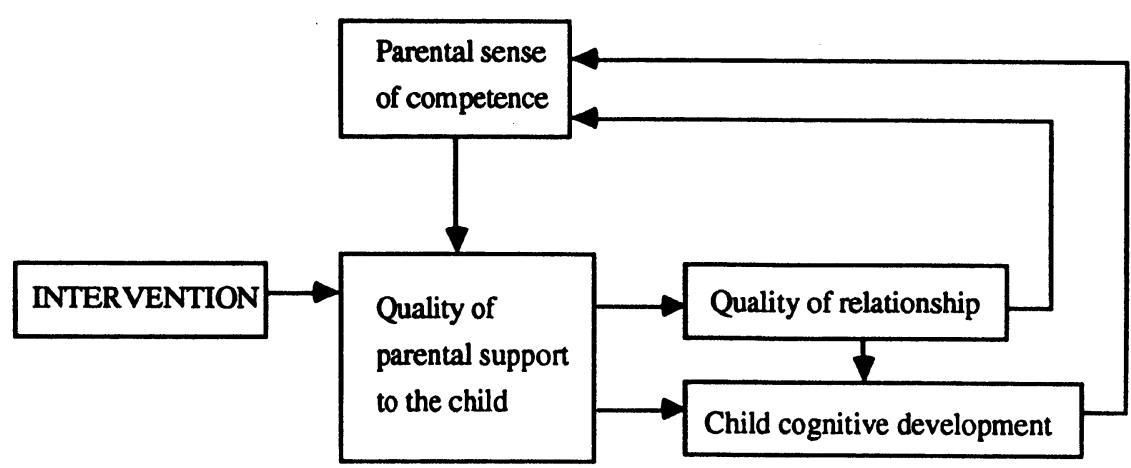

FIG. 1. Hypothesised effects of the Instapje intervention programme on four dependent variables. 
hypothesised that the Instapje programme might ultimately promote the parents' sense of competence as caregivers, provided that they notice the changes in their child and attribute them to their own competence in child rearing. Our expectations about the effects of the programme on the parents' sense of competence ran less high, however, than our expectations regarding the effects on the other three dependent variables, because a parent's sense of competence will improve only after sustained and conspicuous experiences of success in dealing with the child. Thus, we expected that the effect of the intervention on parental sense of competence would be less strong than the effect on the dependent variables placed earlier in the causal sequence in Fig. 1. Improvement of parents' sense of competence would be an important effect of the programme, however, because this change in the parent increases the likelihood of long-term effects of the intervention. As the arrow between parental sense of competence and quality of support in Fig. 1 indicates, parents with a strong sense of competence are expected to be more motivated to support their child and to be more persistent and resourceful in this respect than parents who do not believe in their own efficacy as a caregiver (Bandura, 1977, 1982; Teti \& Gelfand, 1991).

In summary, in the current study we examined the effects of the Instapje programme on four groups of outcome variables in parents and children. Our hypotheses can be summarised as follows. First, we expected to find significant correlations among the four dependent variables depicted in Fig. 1. Second, we expected a positive effect of the intervention on quality of support provided by parents, on children's cognitive development, on the quality of the parent-child relationship and, to a lesser extent, on parents' sense of competence as a caregiver.

\section{METHOD}

\section{Subjects and Design}

The final sample consisted of 75 infants ( 36 boys and 39 girls) and their primary caregivers ( 74 mothers and 1 grandmother; for brevity, we will refer to all of them as "mothers"). Recruitment of families was based on municipal records of the city of Rotterdam (67 families) and on records of infant welfare centres in the cities of Amsterdam ( 5 families) and The Hague ( 3 families). All mothers were of Surinamese origin; 72 of them had immigrated; 3 were born in the Netherlands. Mean duration of stay in the Netherlands was 14.7 years ( $\mathrm{SD}=6.44$; range $2-28$ years). Thirty-five mothers were Creole, 31 were Hindustani, and 9 were from other ethnic groups. According to Dutch standards, the educational level of the mothers was low to moderate (highest educational level four years of secondary school attendance). Teenage mothers, mothers working outside the home 
for more than 20 hours a week, and families with severe problems were excluded from the study. There were 38 single-parent families and 37 families with both parents present.

We recruited 41 families with a 12-month-old child; these families (the intervention group) participated in the intervention programme, starting when the child was 13 months old. Four families did not complete the programme for various reasons: two families left the country for a period longer than four weeks; one mother accepted a full-time job; and one mother's spouse refused further participation. This left 37 families who completed the entire intervention. Immediately after the intervention period, when the children were 18 months old, a post-test was administered. In addition to the intervention group, we recruited 38 families for the control group. These families did not receive the programme; they only participated in the post-test. We recruited these families shortly before their children were 18 months old and tested them immediately on recruitment. We examined the effects of the intervention by comparing the intervention group and the control group in a post-test-only control group design (Campbell \& Stanley, 1964). This design requires that control group and experimental group constitute equivalent samples from the same population. We therefore compared the two groups on a number of demographic variables that are assumed to be related to the core variables under study. Table 1 shows that the groups did not differ in any of these characteristics.

\section{The Intervention}

The Instapje programme aimed at improving the quality of support parents provide to their infants in daily interactions. The 16-week intervention focused on four supportive skills which were subsequently given special attention in consecutive blocks of four weeks each: supportive presence; respecting the child's autonomy; providing structure and limits; and giving high-quality instruction. The (fixed) sequence in which the four supportive skills were highlighted in the course of the programme reflects our assumptions-stated in the Introduction-regarding the order in which these skills gain importance as tools for parents in supporting their child during the second year of life. Before the final 16-week programme was actually implemented, a shorter version was piloted in a sample of 12 Surinam-Dutch families.

The intervention was carried out by specially trained women of Surinamese background who received weekly supervision by the third author during the course of the programme. The intervenors paid weekly home visits to the families, each visit lasting about one-and-a-half hours. During each visit the intervenor first acted as a role model for the mother by 
TABLE 1

Sample Characteristics at Post-test

\begin{tabular}{|c|c|c|c|c|}
\hline \multirow[b]{2}{*}{ Characteristic } & \multirow[b]{2}{*}{$\begin{array}{l}\text { Whole sample } \\
\qquad(N=75)\end{array}$} & \multicolumn{2}{|c|}{ Experimental Groups } & \multirow[b]{2}{*}{$P^{a}$} \\
\hline & & $\begin{array}{l}\text { Control } \\
(n=38)\end{array}$ & $\begin{array}{c}\text { Intervention } \\
\quad(n=37)\end{array}$ & \\
\hline \multicolumn{5}{|l|}{ Target child } \\
\hline Male (\%) & 48.0 & 52.6 & 43.2 & n.s. \\
\hline Firstborn (\%) & 34.7 & 28.9 & 40.5 & n.s. \\
\hline \multicolumn{5}{|l|}{ Mother } \\
\hline Ethnicity & & & & n.s. \\
\hline Creole $(\%)$ & 46.7 & 50.0 & 43.2 & \\
\hline Hindustani (\%) & 41.3 & 34.2 & 48.6 & \\
\hline Other (\%) & 12.0 & 15.8 & 8.1 & \\
\hline Educational level & & & & n.s. \\
\hline Low $(\%)$ & 10.7 & 13.2 & 8.1 & \\
\hline Moderate to low (\%) & 89.3 & 86.8 & 91.9 & \\
\hline Mean age & 28.3 & 28.3 & 28.4 & n.s. \\
\hline Years in the Netherlands & 14.7 & 15.7 & 13.8 & n.s. \\
\hline Living arrangements & & & & \\
\hline Single-parent family (\%) & 50.7 & 52.6 & 48.6 & n.s. \\
\hline
\end{tabular}

${ }^{\mathrm{a}} \mathrm{Chi}$-squares or $\boldsymbol{t}$-tests; significance levels for two-tailed tests.

${ }^{b}$ Low $=$ less than 6 years of schooling; moderate to low $=6-10$ years of schooling.

playing with the child and explaining to her the way she reacted, focusing on the supportive skill that was the topic in that particular block of the programme. Subsequently, the intervenor invited the mother to play with the child and gave feedback on mother-child interactions, again with special attention to the supportive skill that was prominent in that particular block of the programme. The mother was asked to play regularly with the child in the next week (i.e. preferably every day for about 20 minutes) and to keep the suggestions in mind during play interactions as well as during other daily activities with the child.

The programme material consisted of a programme book for the mothers and a set of play materials to be used in the interactions with the child. The materials and the written information were gradually presented to the mothers in the course of the programme. The first part of the book, which was given to the mothers during the first visit, contained information about children's development in the second year and about the four dimensions of parental support, introduced as "four rules of thumb while interacting with your child". During each home visit the mothers received some additional pages of the book with a description of the activities and play materials that had been introduced and demonstrated by the intervenor during that visit. The book contained a great variety of mother-child games and activities. Much attention was given to symbolic play activities (e.g. "cooking" and 
"having tea" together, games with dolls and toy animals), "reading" books together (five picture books were introduced in the course of the programme), and language games. Finally, the book contained a collection of Dutch and Surinamese songs and nursery rhymes, from which the mothers could choose what they and their children liked most.

\section{Procedures and Measures}

The post-test was carried out by the fourth author in two home visits within one week. During these visits mother-child interactions were videotaped, the Bayley Mental Scale of Infant Development was administered, and the mother filled out a questionnaire about her sense of competence in rearing the child. In a previous home visit, the third author had interviewed the intervention group mothers about the way they had carried out and experienced the programme. The interviews revealed that, in general, the programme had been carried out according to its design, implying that a lack of effect of the intervention cannot be attributed to improper implementation of the programme.

Quality of Parental Support. Quality of parental support was observed from a 25-minute mother-child interaction session, videotaped at home. The session consisted of seven episodes. In the first five episodes, each lasting 3 minutes, mothers were asked to let their children solve a problem (a jigsaw puzzle, opening flaps of a puzzle-box, building a tower with cubes, naming and pointing to parts of a doll, and sorting objects), and to help the child whenever she felt she needed to. In the sixth episode, lasting 5 minutes, the mother was asked to read some books with the child. Finally, there was a 5-minute episode of mother-child free play with a set of new toys. On the basis of observation of the whole 25-minute session, caregivers were rated on four 7-point rating scales (Erickson et al., 1985), reflecting the four dimensions of parental support: supportive presence (i.e. expression of positive regard and emotional support to the child), respect for child's autonomy (i.e. recognition of and respect for the child's individuality, motives, and perspectives), structure and limit setting (i.e. adequacy of mother's attempts to establish her expectations for the child's behaviour vs. not communicating her expectations or not enforcing her agenda adequately), and quality of instruction (i.e. the degree to which instructions are timely to the child's focus, stated clearly, paced at a rate that allows comprehension, and graded in logical steps that the child can understand).

The interactions were rated by two observers (the first and second authors) who had gained extensive experience in scoring in earlier research projects and were blind to group assignment of the families. Inter-rater reliabilities, computed on 10 randomly selected and independently scored 
tapes, were $r=0.91$ for supportive presence, $r=0.92$ for respect for child's autonomy, $r=0.86$ for structure and limit setting, and $r=0.93$ for quality of instruction (Pearson correlations).

Quality of the Parent-Child Relationship. Scores for quality of the motherchild relationship, as reflected in children's behaviour towards their mother, were also derived from the videotaped interaction episodes. Each child's interactive behaviour was rated on four 7-point rating scales (Erickson et al., 1985): negativity (i.e. child's anger, dislike, and hostility towards mother), avoidance (i.e. child's tendency to avoid interacting with mother), affection (i.e. positive affect expressed towards mother), and compliance with her suggestions and directions during the instructional tasks.

The child's behaviour was scored by three raters (the second and fourth authors, and a graduate student) who were intensively trained by the first author. Mean inter-rater reliabilities, based on scores of 11 randomly selected subjects, were $r=0.92$ for negativity, $r=0.81$ for avoidance, $r=0.87$ for affection, and $r=0.78$ for compliance (Pearson correlations). As expected, the four scale scores were significantly interrelated. Intercorrelations (scores on negativity and avoidance of mother reversed) ranged from $r=0.39$ to $r=0.87$, mean $r=0.62$, Cronbach's alpha was 0.87 . We computed one composite score for quality of the mother-child relationship by summing the four scale scores after reversing scores for negativity and avoidance.

Child Cognitive Development. Children's level of cognitive functioning was assessed by using the Dutch version of the Bayley (1969) Mental Scale of Infant Development (Van der Meulen \& Smrkovsky, 1983). The test was administered by the fourth author, who was thoroughly trained in the assessments. Level of cognitive development is expressed here in the standardised Mental Developmental Index (MDI), which gives an overall impression of the child's cognitive abilities as compared to a large sample of Dutch same-aged children.

Parental Sense of Competence. To assess parents' sense of competence in child rearing, we used three subscales of a questionnaire described by Engfer and Gavranidou (1987). The subscales were of interest in the framework of our study, because of their specific reference to the mother's sense of competence: depression (5 items referring to feelings of insecurity and uncertainty in child-rearing); stress ( 7 items reflecting overburdening by child-rearing problems); and anxiety (8 items indicating anxious concern for the child's health and development). Scores on the three subscales were signficantly interrelated (between depression and stress $r=0.44$, between 
depression and anxiety $r=0.52$, and between stress and anxiety $r=0.52$; all $P$ s $<0.01$ ). We computed one composite score, by summing the (reversed) scores on the three scales, and labelled it "parental sense of competence". Internal consistency of the combined scale was satisfactory (Cronbach's alpha $=0.78$ ). High scores on this scale indicate a strong sense of competence in child rearing, reflected in self-confidence and a lack of anxiety or overburdening.

\section{RESULTS}

\section{Interrelations of Dependent Variables}

The model in Fig. 1 underlies our hypotheses regarding the effects of the Instapje programme. If the model is valid, significant correlations among the dependent variables, (i.e. quality of parental support, child cognitive development, quality of the mother-child relationship, and parental sense of competence) should be found. This could be easily ascertained by examining the correlations in the control group, which was observed in the "natural setting".

Table 2 shows that the four dimensions of parental support were significantly interrelated, indicating that they indeed represent different aspects of the same construct. Quality of parental support was significantly related to the other three dependent variables: Higher quality of support provided by mothers is associated with greater cognitive competence in their child, with a higher quality of the mother-child relationship, and with a stronger sense of competence in the mothers. There was, however, one insignificant correlation: In contrast to the other three dimensions of parental support, mothers' respect of the child's autonomy proved to be unrelated to their child's cognitive competence.

We also found the expected relation between quality of the mother-child relationship and the child's cognitive competence. Child cognitive

TABLE 2

Intercorrelations among the Dependent Variables of the Instapje Experiment

\begin{tabular}{lccccccc}
\hline Dependent Variable & $1 a$ & $1 b$ & $1 c$ & $1 d$ & 2 & 3 & 4 \\
\hline 1. Quality of parental support & & & & & & & \\
(a) Supportive presence & - & $0.73^{*}$ & $0.73^{*}$ & $0.76^{*}$ & $0.40^{*}$ & $0.63^{*}$ & $0.45^{*}$ \\
(b) Respect for autonomy & & - & $0.50^{*}$ & $0.61^{*}$ & 0.17 & $0.56^{*}$ & $0.39^{*}$ \\
(c) Structure and limit setting & & & - & $0.84^{*}$ & $0.43^{*}$ & $0.69^{*}$ & $0.51^{*}$ \\
(d) Quality of instruction & & & & - & $0.45^{*}$ & $0.69^{*}$ & $0.43^{*}$ \\
2. Child cognitive development & & & & & - & $0.47^{*}$ & $0.44^{*}$ \\
3. Quality of relationship & & & & & & - & $0.60^{*}$ \\
4. Parental sense of competence & & & & & & & - \\
\hline
\end{tabular}

Note: $n=38$, control group. $* P \leqslant 0.01$, one-tailed. 
competence and quality of the relationship in their turn were, as expected, significantly related to the mothers' sense of competence.

\section{Effects of the Intervention}

In order to examine the effects of the intervention, we first compared the mean scores of the intervention and the control group on the separate outcome measures using $t$-tests. We also considered using the MANOVA, because multivariate analysis is theoretically indicated in case of multiple and interrelated dependent variables. An advantage of MANOVA over a series of ANOVAs or $t$-tests, one for each dependent variable, is that it protects against type I error. But, as is indicated by Tabachnick and Fidell (1983, p. 222): “. . . this advantage is seen only when a two-tailed significance test is appropriate. If a one-tailed test is desired, use of MANOVA may result in an unacceptable loss of power." Because the latter was clearly the case in our study - which was led by explicit hypotheses regarding the effects of the intervention-we decided to apply separate $t$-tests.

The results of the $t$-tests and the mean scores of the two groups at the post-test are shown in Table 3. The first aim of the programme was to improve quality of parental support to the child. Table 3 shows a significant positive effect of the intervention on three out of four dimensions of parental support: intervention mothers scored significantly higher than control mothers on supportive presence, respect for the child's autonomy and on structure and limit setting, but not on quality of instruction. Next, we expected that the intervention would improve the child's cognitive competence and the quality of the mother-child relationship. As Table 3 shows, children in the intervention group indeed had significantly higher scores on the Bayley Mental Scale than children in the control group.

TABLE 3

Outcome Comparisons of the Intervention and Control Group: $t$-tests

\begin{tabular}{lcrc}
\hline & \multicolumn{2}{c}{ Group Means } & \\
\cline { 2 - 3 } Dependent Variable & $\begin{array}{c}\text { Control } \\
(n=38)\end{array}$ & $\begin{array}{c}\text { Intervention } \\
(n=37)\end{array}$ & t-value \\
\hline Quality of parental support & & & \\
(a) Supportive presence & $3.63(1.34)$ & $4.19(1.15)$ & $1.93^{*}$ \\
(b) Respect for child's autonomy & $3.84(1.29)$ & $4.41(1.01)$ & $2.11^{*}$ \\
(c) Structure and limit setting & $4.08(1.02)$ & $4.57(1.26)$ & $1.85^{*}$ \\
(d) Quality of instruction & $3.92(1.05)$ & $4.08(1.12)$ & 0.64 \\
Child cognitive development & $106.2(15.4)$ & $112.2(13.4)$ & $1.80^{*}$ \\
Quality of relationship & $15.97(5.26)$ & $15.81(5.07)$ & -0.14 \\
Parental sense of competence & $49.2(6.21)$ & $47.4(6.75)$ & -1.23 \\
\hline
\end{tabular}

Standard deviations are in parentheses.

$* P<0.05$, one-tailed. 
Contrary to our expectations, however, we found no differences in quality of the mother-child relationship between the control and the intervention group. Neither did we find an effect of the programme on the fourth dependent variable: the mother's sense of competence.

Separate analyses of variance (ANOVAs) with the four dimensions of parental support, child cognitive development, quality of the relationship, and parental sense of competence as dependent variables and condition (programme vs. no programme) plus one of the characteristics ethnicity (3), living arrangement (2), educational level of caregiver (2), sex of child (2), and child's birth order (2) (see also Table 1) as independent factors showed no main or interaction effects of these characteristics, except for living arrangement. Main effects of living arrangement were found on mothers' supportive presence $\left[F(1,74)=4.31 ; \quad P<0.05 ; \quad M_{\text {single parent }}=3.61\right.$, $\left.\mathrm{SD}_{\text {single parent }}=1.31 ; M_{\text {two parents }}=4.22, \mathrm{SD}_{\text {two parents }}=1.18\right]$, on mothers' respect for the child's autonomy $\left[F(1,74)=6.25 ; P<0.05 ; \quad M_{\text {single parent }}=3.79\right.$, $\left.\mathrm{SD}_{\text {single parent }}=1.28 ; M_{\text {two parents }}=4.46, \mathrm{SD}_{\text {two parents }}=0.99\right]$, on quality of the relationship $\left[F(1,74)=4.21 ; P<0.05 ; M_{\text {single parent }}=14.71, \mathrm{SD}_{\text {single parent }}=4.97\right.$; $\left.M_{\text {two parents }}=17.11, \mathrm{SD}_{\text {two parents }}=5.08\right]$, and on parental sense of competence $\left[F(1,73)=8.79 ; \quad P<0.01 ; \quad M_{\text {single parent }}=46.3, \quad \mathrm{SD}_{\text {single parent }}=6.52 ;\right.$ $\left.M_{\text {two parents }}=50.4, \mathrm{SD}_{\text {two parents }}=5.86\right]$. This means that mothers in two-parent families, compared with single mothers, have a stronger sense of competence in child rearing, provide better support to the child on two of the four behavioural dimensions under study, and have a better relationship with their child, as apparent from the child's behaviour towards her.

In sum, these results regarding the effects of the programme partially supported our expectations. The programme improved the quality of parental support and children's cognitive development. Quality of the mother-child relationship and the mothers' sense of competence, however, were not affected by the programme.

According to the model underlying our hypotheses, the positive effect of the intervention on children's cognitive development should have been brought about by the effect of the programme on their mothers' behaviour. Theoretically, however, the intervention group children's higher level of cognitive competence might also be explained by their weekly interactions with the intervenor, or by playing with the new toys presented during the programme. In order to gain more insight into this matter, we used the LISREL VII statistical programme (Jøreskog \& Sørbom, 1989) to examine whether the effect of the intervention on quality of parental support was related to its effect on children's cognitive competence. In the analysis, the intervention programme was introduced as the independent variable and quality of parental support and children's level of cognitive development as dependent variables. Quality of parental support was represented by the three dimensions of parental support on which the intervention had a 
positive effect. We found that the association between the intervention programme (as a dummy variable) and the latent construct quality of parental support was 0.21 . The association between quality of parental support and the child's level of cognitive development was 0.35 . The association between the intervention programme and the child's level of cognitive development was 0.14 . Deleting this last (nonsignificant) path from the model resulted in a reduction of only 1.57 in chi-square. This change in chi-square is not significant and suggests that the most parsimonious model is one that excludes this path. The chi-square and goodness-of-fit index indicate that the reduced model fits the data well $\left(\chi^{2}=7.41, d f=5 ; G F I=0.964\right)$. In the reduced model the association between the intervention programme and the quality of parental support was 0.21 , the association between the quality of parental support and children's level of cognitive development was 0.38 . These findings support our assumption that the effect of the intervention programme on children's cognitive development was mediated by the effect of the intervention upon quality of parental support.

\section{DISCUSSION}

The hypotheses tested in this study were derived from a model specifying the effects of the intervention on several conceptually interrelated outcome variables. We did not pretend to test the validity of this model in the current investigation; the study was not set up for that purpose. We used the model primarily as an aid in designing the intervention and the effect-study. In this section we will use it as a guide in interpreting the pattern of our findings.

First, the hypothesised correlations among the four outcome variables were all significant and in the expected direction. Except for the relation between quality of support provided by the mother and quality of the mother-child relationship, which were both observed during the same mother-child interaction episode, the possibility must be excluded that the correlations are due to shared method variance, because scores were obtained using different methods and data from different sources. Quality of support was observed directly in mother-child interactions, children's cognitive development was assessed using a standardised test, and scores for parental sense of competence were derived from a questionnaire filled out by the mothers.

Second, the pattern of intervention effects appears to be consistent with and interpretable in terms of the model. The first and most immediate goal of the Instapje programme was to improve the quality of support parents provide to their children. The expected effect of the intervention on parental support was indeed found on three of the four dimensions of parental behaviour we sought to improve. Given this effect of the intervention on 
quality of support, we expected an improvement of children's cognitive development and of quality of the mother-child relationship. As expected, children in the experimental group scored significantly higher on the Bayley Mental Scale than their control group counterparts. The results of our LISREL analyses suggest that this effect of the programme may indeed be attributed to the improvement of the quality of parental support brought about by the programme. It should be kept in mind, however, that the lack of longitudinal data of the present study does not allow us to draw firm conclusions regarding causal relations within our model.

Contrary to our expectations, the intervention did not affect the quality of the mother-child relationship as evidenced in children's behaviour towards their mother. Attachment theorists assume that the organisation of a child's behaviour towards a given caregiver is a product of their interaction history. If children experience a parent as available and emotionally supportive, they are assumed to construct an "internal working model" of the parent as a firm and dependable source of support. This internal working model guides the child's behaviour in further interactions (cf. Bretherton, 1985). At the age of 13 months, when the Instapje programme started, children's internal working model of their mother may already be fairly stable, because it is already based on a substantial amount of interaction. Moreover, it has been assumed that internal working models are resistant to change because new information is assimilated to existing models (Bowlby, 1980). Once children have established a relatively stable working model of their caregiver, changes can only be brought about by conspicuous and sustained changes in the caregiver's behaviour towards the child (Vaughn, Egeland, Sroufe, \& Waters, 1979). The absence of an intervention effect on children's behaviour towards their mother, despite the improvement we found in the quality of support she provides to her child, brings us to the conclusion that the changes in maternal behaviour brought about by the programme were not big or sustained enough to cause a change in the child's working model of the mother. Extension of the intervention beyond the current period of 16 weeks might raise the effectiveness of the programme in this respect.

Given the lack of effect on children's behaviour towards their mother, the absence of an effect of the intervention upon the mothers' sense of competence was not surprising. As shown in the model in Fig. 1, we assumed that improvement of childrens' cognitive competence and of the quality of their behaviour towards the mother might promote her sense of competence, provided that she notices the changes in the child and attributes them to her own competence in child rearing. Although the child's cognitive improvements during the programme were noticed by many mothers (as was revealed in the post-intervention interviews), the mothers may have attributed them to other causes, such as the child's playing with the intervenor or with the new play materials. A change in the child's behaviour 
directed towards the mother, if brought about by the intervention, might have had a much greater impact upon her sense of competence than the child's changes in cognitive functioning. As mentioned in the Results section, quality of the relationship, as reflected in children's behaviour towards their mother, appears to be stronger related to the mother's sense of competence than the child's level of cognitive development (correlations of 0.60 and 0.44 , respectively). These findings are in line with the results of a study by Teti and Gelfand (1991), indicating that infant difficultness is a powerful predictor of the mother's sense of self-efficacy as a caregiver.

Although the intervention had the expected effect on three out of four dimensions of parental support, the programme did not improve the quality of the instructions the mothers provided to their child. This may have been caused by a relative lack of attention given to this behavioural dimension during the intervention. The four dimensions of support were subsequently focused on in the course of the programme; the skill of providing good quality instructions was explicitly brought under the attention of the mothers only in the fourth and last block. Therefore, mothers may not have had enough opportunity to integrate the skill in their behavioural repertoire. This is one more reason to assume that extension of the programme may enhance and consolidate its effects.

Interpretation of the findings of our study in terms of the underlying model brings us to the conclusion that the Instapje programme in its current form is essentially effective in enhancing quality of parental support and child cognitive performance. Probably the intervention did not last long enough to work through in the other outcome variables as well. Therefore, we currently extended the 16 -week programme by an extra 10 weeks, without changing the basic formula of the intervention. In the next two years, the extended version of the programme will be provided to Surinam-Dutch families in five Dutch cities. Future research may reveal whether the extension of the intervention will indeed lead to the expected enhancement of its effectiveness.

Manuscript received March 1995 Revised manuscript received December 1995

\section{REFERENCES}

Arend, R., Gove, F.L., \& Sroufe, L.A. (1979). Continuity of individual adaptation from infancy to kindergarten: A predictive study of ego-resiliency and curiosity in preschoolers. Child Development, 50, 950-959.

Bandura, A. (1977). Self-efficacy: Toward a unifying theory of behavioral change. Psychological Review, 84, 191-215.

Bandura, A. (1982). Self-efficacy mechanisms in human agency. American Psychologist, 37 , 122-147. 
Bayley, N. (1969). Bayley Scales of Infant Development. New York: Psychological Corporation.

Block, J.H., \& Block, J. (1980). The role of ego-control and ego-resiliency in the organization of behavior. In W.A. Collins (Ed.), Minnesota Symposia on Child Psychology (Vol. 13, pp. 39-101). Hillsdale, NJ: Lawrence Erlbaum Associates Inc.

Bornstein, M.H. (1985). How infant and mother jointly contribute to developing cognitive competence in the child. Proceedings of the National Academy of Science, 82, 7470-7473.

Bowlby, J. (1980). Attachment and loss: Vol. 3. Loss, sadness, and depression. New York: Basic Books.

Bretherton, I. (1985). Attachment theory: Retrospect and prospect. In I. Bretherton \& E. Waters (Eds.), Growing points of attachment theory and research. Monographs of the Society for Research in Child Development, 50, 3-35.

Bruner, J.S. (1983). Child's talk: Learning to use language. Oxford: Oxford University Press.

Bus, A.G., \& Van IJzendoorn, M.H. (1992). Patterns of attachment in frequently and infrequently reading mother-child dyads. Journal of Genetic Psychology, 153, 395-403.

Campbell, D., \& Stanley, C. (1964). Experimental and Quasi-experimental designs for research on teaching. In N. Cage (Ed.), Handbook of research on teaching. Chicago: Rand \& McNally.

Elicker, J. Englund, M., \& Sroufe, L.A. (1993). Predicting peer competence and peer relationships in childhood from early parent-child relationships. In R. Parke \& G. Ladd (Eds.), Family-peer relationships: Modes of linkage. Hillsdale, NJ: Lawrence Erlbaum Associates Inc.

Engfer, A., \& Gavranidou, M. (1987). Antecedents and consequences of maternal sensitivity: A longitudinal study. In H. Rauh \& H.C. Steinhausen (Eds.), Psychobiology and early development (pp. 71-99). Amsterdam: North Holland.

Erickson, M.F., Sroufe, L.A., \& Egeland, B. (1985). The relationship between quality of attachment and behavior problems in preschool in a high-risk sample. In I. Bretherton \& E. Waters (Eds.), Growing points of attachment theory and research. Monographs of the Society for Research in Child Development, 50, 147-166.

Erikson, E.H. (1963). Childhood and society (2nd ed.). New York: Norton.

Gray, G.W., \& Klaus, R. (1970). The early training project: A seventh-year report. Child Development, 41, 909-924.

Heckhausen, J. (1987). Balancing for weaknesses and changing developmental potential: A longitudinal study of mother-infant dyads in apprenticeship interactions. Developmental Psychology, 23, 762-770.

Isabella, R.A. (1994). Origins of attachment: Maternal interactive behavior across the first year. Child Development, 64, 605-621.

Jap-A-Joe, S.R., \& Leseman, P.P.M. (1993). Surinaamse opvoedingstradities: Behoud en verandering na migratie [Surinamese pedagogical traditions: Maintenance and change after migration]. Rotterdam: RISBO.

Jøreskog, K.G., \& Sørbom, D. (1989). LISREL: Analysis of linear structural relationships by maximum likelihood, instrumental variables and least squares methods (Version VII). Mooresville, IN: Scientific Software.

Lieberman, A.F., Weston, D.R., \& Pawl, J.H. (1991). Preventive intervention and outcome with anxiously attached dyads. Child Development, 62, 199-209.

Mahler, M., Pine, R., \& Bergman, A. (1975). The psychological birth of the human infant. New York: Basic Books.

Matas, L., Arend, R.A., \& Sroufe, L.A. (1978). Continuity of adaptation in the second year: The relationship between quality of attachment and later competence. Child Development, 49, 547-556.

Pels, T. (Ed.) (1990). Opstap under scrutinity: An assessment of the materials and methods of the Opstap-programme. Amsterdam: Averroès. 
Petersen, B., \& De Keyzer, M. (1991) Het speciaal onderwijs en het onderwijsvoorrangsbeleid [Special education and policy in educational priority]. Nijmegen: ITS.

Riksen-Walraven, J.M.A. (1978). Effects of caregiver behavior on habituation rate and self-efficacy in infants. International Journal of Behavioral Development, 1, 105-130.

Riksen-Walraven, J.M.A. (1991). Die Entwicklung kindlicher Kompetenz im Zusammenhang mit sozialer Unterstützung [Competence development in relation to social support]. In F.J. Mönks \& G. Lehwald (Eds.), Neugier, Erkundung und Begabung bei Kleinkindern (pp. 77-93). München: Reinhardt.

Rogoff, B. (1990). Apprenticeship in thinking: Cognitive development in social context. Hillsdale, NJ: Lawrence Erlbaum Associates Inc.

Sander, L.W. (1975). Infant and caretaking environment. In E.J. Anthony (Ed.), Explorations in child psychiatry. New York: Plenum.

Seitz, V., \& Apfel, N.H. (1994). Parent-focused intervention: Diffusion effects on siblings. Child Development, 65, 677-683.

Sigman, M., Neumann, C., Carter, E., Cattle, D.J., D’Souza, S., \& Bwibo, N. (1988). Home interactions and the development of Embu toddlers in Kenya. Child Development, 59, 1251-1261.

Spangler, G. (1989). Toddlers' everyday experiences as related to preceding mental and emotional disposition and their relationship to subsequent mental and motivational development. International Journal of Behavioral Development, 12, 285-303.

Sroufe, L.A. (1979). The coherence of individual development. American Psychologist, 34, 834-841.

Suess, G.J., Grossmann, K.E., \& Sroufe, L.A. (1992). Effects of infant attachment to mother and father on quality of adaptation in preschool: From dyadic to individual organisation of self. International Journal of Behavioral Development, 15, 43-65.

Tabachnick, B.G., \& Fidell, L.S. (1983). Using multivariate statistics. New York: Harper \& Row.

Tamis-LeMonda, C.S., \& Bornstein, M.H. (1994). Specificity in mother-toddler languageplay relations across the second year. Developmental Psychology, 30, 283-292.

Tamis-LeMonda, C.S., Bornstein, M.H., Cyphers, L., Toda, S., \& Ogino, M. (1992). Language and play at one year: A comparison of toddlers and mothers in the United States and Japan. International Journal of Behavioral Development, 11, 415-432.

Teti, D.M., \& Gelfand, D.M. (1991). Behavioral competence among mothers of infants in the first year: The mediational role of maternal self-efficacy. Child Development, 62, 918-929.

Tesser, P., Mulder, L., \& Van der Werf, G. (1991). De eerste fase van de longitudinale OVB-onderzoeken. Het leerlingenonderzoek [First stage of the longitudinal studies regarding the educational priority policy]. Nijmegen: ITS.

Van Aken, M.A.G. (1992). The development of general competence and domain-specific competencies. European Journal of Personality, 6, 267-282.

Van den Boom, D.C. (1994). The influence of temperament and mothering on attachment and exploration: An experimental manipulation of sensitive responsiveness among lower-class mothers with irritable infants. Child Development, 65, 1457-1478.

Van der Meulen, B.F., \& Smrkovsky, M. (1983). BOS 2-30 Bayley Ontwikkelingsschalen [Bayley Scales of Infant Development]. Lisse, The Netherlands: Swets \& Zeitlinger.

Van IJzendoorn, M.H. (1990). Attachment in Surinam-Dutch families: A contribution to the cross-cultural study of attachment. International Journal of Behavioural Development, 13, 333-344.

Vaughn, B., Egeland, B., Sroufe, L.A., \& Waters, E. (1979). Individual differences in infant-mother attachment at twelve and eighteen months: Stability and change in families under stress. Child Development, 50, 971-975. 


\section{RIKSEN-WALRAVEN ET AL.}

Vygotsky, L.S. (1978). Mind in society: The development of higher psychological processes. Oxford: Oxford University Press.

Wachs, T.D., Bishry, Z., Sobhy, A., McCabe, G., Galal, O., \& Shaheen, F. (1993). Relation of rearing environment to adaptive behavior of Egyptian toddlers. Child Development, 64, $586-604$. 